\title{
Changes in Depression and Physical Activity Among College Students on a Diverse Campus After a COVID-19 Stay-at-Home Order
}

Courtney Coughenour ( $\nabla$ courtney.coughenour@unlv.edu )

University of Nevada, Las Vegas https://orcid.org/0000-0001-6979-4660

Maxim Gakh

University of Nevada, Las Vegas

Jennifer R. Pharr

University of Nevada, Las Vegas

Timothy Bungum

University of Nevada, Las Vegas

Sharon Jalene

University of Nevada, Las Vegas

\section{Research Article}

Keywords: COVID-19, college students, mental health, physical activity, depression, stay-at-home order

Posted Date: September 3rd, 2020

DOl: https://doi.org/10.21203/rs.3.rs-70471/v1

License: (9) This work is licensed under a Creative Commons Attribution 4.0 International License. Read Full License 


\section{Abstract}

The numerous negative health impacts of COVID-19, which include expected changes to psychiatric illness and physical activity (PA), are disproportionately distributed in the United States. Mental illnesses and physical inactivity are prevalent among U.S. college students. This study examined whether there was a change in minutes of PA and depression scores after a stay-at-home order and examined predictors of these changes. An online survey was sent to all undergraduate and graduate students attending a large, diverse university via an electronic newsletter. The survey requested information about demographic and academic data, cardiorespiratory fitness, and depression symptoms. Paired t-tests and logistic regression were employed. Our sample $(n=194)$ was predominantly female $(73 \%)$, young (mean age of 25), not a sexual minority (82\%), and had a mean 3.4 GPA. Students reported worse depression scores $(p<0.01)$ and fewer minutes of PA $(p=0.01)$ after the stay-at-home order. There was a small but significant $(p=0.04)$ correlation between changes in total minutes of PA and depression scores. Senior $(p=0.05)$ and Hispanic $(p=0.03)$ students were less likely to report worsening depression scores than freshmen and white students, respectively. Asian students were significantly more likely than white students to report decreased PA. This study suggests that COVID-19 and its consequences may be contributing to reduced PA and greater depression symptoms in college students and that sub-groups have been affected differently. Targeted interventions to promote PA and support mental health may bolster the ability for resilience of college students.

\section{Introduction}

The COVID-19 pandemic has disrupted global health systems and services [1] and upended economies across the world [2]. It has so far led to at least 21 million cases and 755,786 deaths worldwide in far less than its first year [3]. The global response to COVID-19 includes a race to roll out testing, trace contacts, quarantine and isolate individuals, slow the movement of people, reduce person-to-person interactions, develop a vaccine, find effective medical interventions, and bolster public health and healthcare systems. Yet the consequences of COVID-19, especially in the longer-term, are just beginning to bear out [4]. The United States has been impacted especially hard by this pandemic, with over 167,000 deaths and well over 5.2 million cases of COVID-19 as of mid-August - and counting [5]. While U.S. federal efforts include tracking the disease, boosting research, overseeing vaccine development, and attempting to stimulate the economy [6], responses of U.S. state and local governments have varied and include efforts to restrict the movement and gathering of people as well as closing and tightly controlling re-opening of businesses and organizations, including academic institutions [7].

Not surprisingly to health professionals, COVID-19 is affecting populations disproportionately [8]. For example, Gupta and colleagues determined that some of the main risk factors for mortality related to COVID-19 for critically-ill patients include pre-existing medical conditions such as coronary heart disease, cancer, acute organ disfunction, and obesity as well as older age, being male, and admission to a hospital with fewer intensive care unit beds [9]. These inequities, however, run deeper than just pre-existing health conditions. Some of the most impacted communities in the U.S. have been racial and ethnic minorities, 
particularly African Americans, Hispanics, American Indians, Alaskan Natives, and Pacific Islanders $[8,10]$. COVID-19 has highlighted existing social and economic disparities, which are typically attributed to preexisting health conditions and disparities in housing and employment $[8,10]$. In addition, our understanding of how COVID-19 impacts vulnerable populations is just beginning to unfold. For instance, COVID-19 may create barriers for individuals with opioid use disorder to access medications and services, and perhaps lead to increases in opioid overdoses [11].

As the pandemic continues, an important sub-population that deserves study, though typically healthy and robust, are college students. College students have escaped neither COVID-19 infections nor its other consequences. In a March to May 2020 survey of over 18,000 U.S. students across 14 campuses, few students reported confirmed $(0.6 \%)$, probable $(1.7 \%)$, and possible $(13 \%)$ cases of COVID19 [12]. However, outbreaks among college students have occurred [13].

Furthermore, the impacts of COVID-19 on the health and well-being of college students go well beyond contracting the disease. About two-thirds of students recently surveyed reported that they were "very/extremely concerned" about the pandemic's duration, that individuals they cared about would contract COVID-19, and increased financial stress [12]. They also reported increases in anxiety and depression, and academic performance suffering due to mental health concerns [12]. These results are consistent with findings by Huckins and colleagues, who found that U.S. college students exhibited greater anxiety and depression and increased sedentary behavior in the first few months of the COVID-19 pandemic [14]. Because of the major stressors associated with COVID-19, such as the imposition of unfamiliar public health measures, potential financial losses, and the reality of life in a pandemic, there will likely be an uptick in psychiatric illness in the general population [15]. Since college students are already a high-risk population for depression, suicide, and suicide ideation $[16,17,18,19,20,21]$, they warrant study at this time.

Even before the start to this pandemic, depression was a major problem among college students. For those who pursue higher education, the inherent demands of academic performance, adjustments to independent living, and financial stress can intensify negative affects [22]. Aggregated data from a 2013 meta-analysis [19] indicate that approximately $35.0 \%$ of students experience moderate to severe depression while in universities. Comparatively, the National Institute of Mental Health reports that approximately $7.1 \%$ of American adults had a major depressive episode in the last year (ages 18 to 25 $13.1 \%$; ages 26 to $49-7.7 \%$; ages $50+-4.7 \%$ ) [23]. In a diverse college environment, demographic factors, including sex [24, 25], sexual orientation [26, 27] and race and ethnicity [24, 28, 29] can exacerbate symptoms. Birth-sex designation and sexual orientation are also associated with reported depression [24, $25,26]$. Male college students are more likely to self-silence symptoms of depression compared to females [24], and female college students routinely report higher levels of depression and stress than males but are more likely to seek help [25]. Students in a sexual gender minority (SGM) also report higher levels of depression $[26,30]$. Research studies $[31,32,33]$ and literature reviews $[34,35,36]$ indicate that depression is two to four times more prevalent in SGM populations and bisexual individuals are the most vulnerable to depression and depression-related suicide [34,36]. Race and ethnicity are also associated 
with increased levels of reported depression in some cases [28, 29, 37]. Asian-American college students report significantly higher rates of depression than Caucasian American students [29], which is concerning because Asian-Americans are more likely to quell depressive symptoms than other ethnic groups [24]. African American students, with equivalent socioeconomic status to their peers, experience higher levels of depression [28]. Hispanic students also have been found to have higher rates of depression at predominantly Caucasian [37] and ethnically diverse universities [37, 38].

Physical activity can be a powerful counterforce against depression. The general benefits of physical activity for adults are well documented and include improved mental health and brain health. Other benefits include weight management; reduced risk of developing cardiovascular disease, Type 2 diabetes, and certain cancers; improved bone and muscle health; and reduced risk of all-cause mortality [39]. However, a systematic review of the literature suggests that over half of undergraduate students in the U.S. and Canada do not meet physical activity guidelines [40]. A fall 2019 survey of over 38,000 U.S. college students found that $67.6 \%$ of respondents met guidelines for aerobic activity but only $40.3 \%$ met both aerobic activity and strength training standards [41, 42]. Since college students are overburdened with depression, and physical activity can both prevent depression and reduce its symptoms [43, 44], it is critical to study how depression and physical activity among college students are changing during the COVID-19 crisis.

In light of the COVID-19 pandemic and the lingering and inter-related issues of physical activity and depression among college students, the purpose of this study was to: (1) determine if there was a change in participants' physical activity minutes prior to versus after stay-at-home orders were issued in the State of Nevada, (2) determine if there was a change in depression scores prior to versus after stay-at-home orders, and (3) understand predictors of depression score and physical activity changes among college students.

\section{Methods}

\section{Study Design, Setting, and Participants}

This cross-sectional study was conducted at one of the most racially diverse universities in the United States located in Southern Nevada between May 7th and May 28, 2020. A request for students to complete an online survey hosted through Qualtrics was sent to students as part of a weekly e-newsletter that is disseminated to all student email addresses. The request was sent about one month after the state governor issued a stay-at home-order and the university campus closed, with all classes being converted to remote instruction. Participants were both graduate and undergraduate students over the age of 17 . They were able to complete the 10-minute survey anonymously and some received extra credit in a course for participating.

\section{Ethical Approval}


This study was approved by the University of Nevada, Las Vegas, Institutional Review Board. Prior to starting the survey, participants were provided informed consent materials and had to click "agree" to participate in the survey.

\section{Data Sources and Measures}

Participants were asked to provide demographic information, including age, sex, sexual orientation, and race/ethnicity in addition to student information, such as class standing (freshman, sophomore, junior, senior, graduate student) and current grade point average (GPA). Participants were asked questions about the minutes of physical activity that they typically engaged in during a normal week prior to the formal stay-at-home order issued on March $31^{\text {st }}$ and during a typical week since the stay-at-home order. A series of questions from a previously-validated, non-exercise algorithm were used to estimate their cardiorespiratory fitness (eCRF) [45]. Lastly, participants were asked a series of questions from the Patient Health Questionnaire - PHQ-9 focused on the same two timeframes: prior to the stay-at-home order and during the two weeks before completing the survey but after issuance of the stay-at-home order.

\section{Estimated Cardiorespiratory Fitness}

A previously published non-exercise algorithm that can be employed to estimate cardiorespiratory fitness (eCRF) was used in this study. It has been found to be predictive of depression among college students [46]. It has also been found to be reasonably accurate in predicting sex-specific relative V02 peak in healthy adults [45]. Variables in the algorithm include age, body composition (body mass index or waist circumference), resting heart rate (RHR), and a physical activity index (PA-I). The resulting data are reported in relative terms $(\mathrm{mL} \cdot \mathrm{kg}-1 \cdot \min -1)$. To obtain the PA-I, questions regarding exercise frequency, duration, and intensity were scored and weighted according to a previously published PA-I [45]. For RHR, participants were asked to be seated while completing the survey and to measure their RHR after five minutes of quiet sitting. Because of inconsistent self-reported waist circumference measurements and difficulty in obtaining the measurement (e.g. tape measures not available), the body mass index (BMI) model was selected to be used for this study:

Men $(\mathrm{R} 2=0.59, \mathrm{SEE}=5.8): 92.05-(0.327 \mathrm{AGE})-(0.933 \mathrm{BMI})-(0.167 \mathrm{RHR})+(0.257 \mathrm{PA}-\mathrm{I})$

Women $(\mathrm{R} 2=0.57, \mathrm{SEE}=5.1): 70.77-(0.244 \mathrm{AGE})-(0.749 \mathrm{BMI})-(0.107 \mathrm{RHR})+(0.213 \mathrm{PA}-\mathrm{I})$

\section{Patient Health Questionnaire (PHQ-9)}

The PHQ-9 is a brief, validated depression questionnaire used for screening, monitoring, and measuring the severity of symptoms and is appropriate for both research and clinical practice [47]. Nine questions incorporate Diagnostic and Statistical Manual of Mental Disorders, Version Four (DSM-IV) criteria.

Participants were asked to report the frequency of problems occurring two weeks prior to March $31^{\text {st }}$ (before issuance of the stay-at-home order) and during the two weeks prior to taking the survey (after 
issuance of the stay-at-home order). Responses for each question were scored from $0-3(0=$ Not at All, 1 = Several Days, 2 = More than Half the Days, or $3=$ Nearly Every Day, respectively). Internal reliability (Cronbach's a $=0.89$ ) and test-retest reliability (kappa of 0.84 ) have been reported as excellent for the PHQ-9 [48]. The total score on this instrument can range from 0 (lowest depression) to 27 (highest depression). We used the total score for this analysis.

\section{Variables}

The variables of interest included total weekly physical activity minutes and PHQ-9 scores prior to and after issuance of the stay-at-home order. To achieve aim 3, additional variables used in the logistic regression model included characteristics found to impact depression scores among college students in previous work (eCRF, GPA, sexual orientation [46], sex [24], age [23], and class standing [49]).

\section{Statistical Analysis}

Paired t-tests were used to determine if there were differences in total physical activity minutes and PHQ-9 scores prior to and after issuance of the stay-at-home order. We calculated the pre-post difference in total physical activity minutes and PHQ-9 scores and conducted a correlation analysis between PHQ-9 difference and total physical activity minutes difference. Lastly, we dichotomized PHQ-9 and physical activity difference scores into a binary outcome where $0=$ PHQ-9 score got better or stayed the same and $1=$ PHQ-9 score got worse and where $0=$ physical activity stayed the same or increased and $1=$ physical activity decreased. Logistic regression was used to model these outcomes using the previously mentioned covariates to determine what might predict the change in PHQ-9 scores or minutes of physical activity. We used SPSS version 24 to complete these analyses.

\section{Results}

Our sample consisted of 194 participants who completed both the PHQ-9 and weekly minutes of physical activity questions. Demographic and academic characteristics are provided in Table 1. The participants' mean age was 25 years old and participants had a relatively high mean GPA at 3.4. Nearly three-fourths of the participants were female (72\%) and the majority were not a sexual or gender minority. Sixty-three percent of the participants had a worse (higher) PHQ-9 score after the stay-at-home order was issued compared to before its issuance (Table 1).

Paired t-tests revealed a statistically significant difference in both PHQ-9 scores and weekly minutes of physical activity prior to versus after issuance of the stay-at-home order, with a mean PHQ-9 score prior to stay-at-home orders of 5.58 compared to a mean post order score of $9.61(t=9.14, p<0.01)$. Participants reported significantly fewer weekly minutes of physical activity with an average of 409 minutes prior to the stay-at-home order and a mean of 330 minutes post stay-at-home order $(t=2.58$, $\mathrm{p}=0.01)$. There was a significant but small correlation between the change in weekly physical activity minutes and the change in PHQ-9 scores (Pearson correlation $=-0.151, \mathrm{p}=0.04$ ). 
Our logistic regression analyses found few significant associations between the potential predictor variables and the change in PHQ-9 score or weekly physical activity minutes (Table 2 and Table 3). For change in PHQ-9 score, being a senior and being Hispanic was associated with a decreased probability of PHQ-9 score getting worse compared to the reference groups of freshmen and White (Table 2). For change in weekly physical activity minutes, being Asian was associated with an increased probability of decreased minutes of physical activity compared to the reference group of White (Table 3).

\section{Table 1: Participant Demographic and Student Characteristics and Paired t-tests Results from a spring 2020 survey conducted at a diverse urban campus $(n=194)$.}

\begin{tabular}{|c|c|c|}
\hline Continuous Variables & Mean (SD) & \\
\hline Age & $25.11(7.84)$ & \\
\hline Grade point average (GPA) & $3.4118(0.46)$ & \\
\hline Estimated cardiorespiratory fitness (eCRF) & $66.02(44.70)$ & \\
\hline Categorical Variables & $\mathbf{N}(\%)$ & \\
\hline Sex & & \\
\hline Male & $53(27.3)$ & \\
\hline Female & $140(72.2)$ & \\
\hline Transgender & $1(0.5)$ & \\
\hline Sexual Gender Minority & & \\
\hline 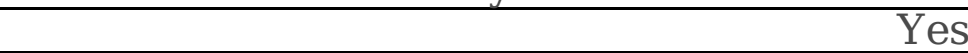 & $35(18.0)$ & \\
\hline $\mathrm{No}$ & $159(82.0)$ & \\
\hline Race & & \\
\hline White & $71(36.6)$ & \\
\hline Asian & $46(23.7)$ & \\
\hline Black & $25(12.9)$ & \\
\hline Hispanic & $34(17.5)$ & \\
\hline Other & $17(8.7)$ & \\
\hline Class Standing & & \\
\hline Freshman & $16(8.2)$ & \\
\hline Sophomore & $26(13.4)$ & \\
\hline Junior & $64(33.0)$ & \\
\hline Senior & $48(24.7)$ & \\
\hline Graduate/Other & $40(20.6)$ & \\
\hline Change in PHQ-9 Score & & \\
\hline No change or better & $71(36.6)$ & \\
\hline Worse & $123(63.4)$ & \\
\hline Paired T-tests & Mean (SD) & t-test (p-value) \\
\hline PHQ-9 Score & & $9.14(p<0.01)$ \\
\hline PHQ-9 score prior to the order & $(4.80)$ & \\
\hline PHQ-9 score after the order & $9.61 \quad(6.91)$ & \\
\hline Minutes of Physical Activity & & $2.58(\mathrm{p}=0.01)$ \\
\hline Minutes of physical activity prior to the order & $409.31(420.77)$ & \\
\hline Minutes of physical activity after the order & $330.82(353.18)$ & \\
\hline
\end{tabular}

Table 2: Univariate Logistic Regression Results Examining Factors Related to a Change in Patient Health Questionnaire (PHQ-9) Score from a spring 2020 survey conducted at a diverse urban campus $(n=194)$. 


\begin{tabular}{|c|c|c|c|c|c|}
\hline Continuous Variables & B & S.E. & Wald & p-value & $\operatorname{Exp(B)}$ \\
\hline Change in physical activity minutes & -0.001 & 0.00 & 1.978 & 0.160 & 0.999 \\
\hline Age & -0.02 & 0.02 & 0.78 & 0.38 & 0.98 \\
\hline GPA & 0.47 & 0.32 & 2.08 & 0.15 & 1.60 \\
\hline $\mathrm{eCRF}$ & 0.03 & 0.02 & 2.21 & 0.14 & 1.03 \\
\hline \multicolumn{6}{|l|}{ Categorical Variables } \\
\hline \multicolumn{6}{|l|}{ Class standing } \\
\hline First-year & REF & REF & REF & REF & REF \\
\hline Sophomore & -0.47 & 0.78 & 0.36 & 0.55 & 0.63 \\
\hline Junior & -0.96 & 0.69 & 1.91 & 0.17 & 0.39 \\
\hline Senior & -1.38 & 0.70 & 3.87 & 0.05 & 0.25 \\
\hline Graduate/Other & -0.85 & 0.72 & 1.38 & 0.24 & 0.43 \\
\hline$\overline{\text { Race }}$ & -0.09 & 0.09 & 0.92 & 0.34 & 0.92 \\
\hline White & REF & REF & REF & REF & REF \\
\hline Asian & -0.49 & 0.40 & 1.52 & 0.22 & 0.61 \\
\hline Black & -0.53 & 0.49 & 1.19 & 0.28 & 0.59 \\
\hline Hispanic & -0.94 & 0.43 & 4.68 & 0.03 & 0.39 \\
\hline Other & -0.24 & 0.57 & 0.19 & 0.67 & 0.78 \\
\hline \multicolumn{6}{|l|}{ SGM } \\
\hline No & REF & REF & REF & REF & REF \\
\hline Yes & 0.44 & 0.41 & 1.17 & 0.28 & 1.56 \\
\hline Sex & 0.10 & 0.33 & 0.10 & 0.75 & 1.11 \\
\hline Male & REF & REF & REF & REF & REF \\
\hline Female & 0.06 & 0.33 & 0.03 & 0.87 & 1.06 \\
\hline Transgender* & & & & & \\
\hline
\end{tabular}

REF $=$ reference group. ${ }^{*}=$ cell size too small for analysis. GPA=grade point average, eCRF $=$ estimated cardiorespiratory fitness

Table 3: Univariate Logistic Regression Results Examining Factors Related to a Change in Physical Activity Minutes from a spring 2020 survey conducted at a diverse urban campus $(n=194)$. 


\begin{tabular}{|l|l|l|l|l|c|}
\hline Continuous Variables & B & S.E. & Wald & p-value & Exp(B) \\
\hline Change in PHQ-9 score & 0.036 & 0.024 & 2.174 & 0.140 & 1.036 \\
\hline Age & -0.02 & 0.02 & 0.49 & 0.48 & 0.99 \\
\hline GPA & 0.51 & 0.36 & 2.04 & 0.15 & 1.67 \\
\hline eCRF & 0.03 & 0.02 & 2.55 & 0.11 & 1.03 \\
\hline Categorical Variables & & & & & \\
\hline Class standing & & & & & \\
\hline Freshman & REF & REF & REF & REF & REF \\
\hline Sophomore & -0.86 & 0.77 & 1.21 & 0.27 & 0.42 \\
\hline Junior & -1.130 & 0.71 & 2.52 & 0.11 & 0.32 \\
\hline Senior & -0.69 & 0.73 & 0.90 & 0.34 & 0.50 \\
\hline Graduate/Other & -1.15 & 0.74 & 2.417 & 0.12 & 0.32 \\
\hline & & & & & \\
\hline White & REF & REF & REF & REF & REF \\
\hline Asian & 0.84 & 0.40 & 4.35 & $\mathbf{0 . 0 4}$ & 2.32 \\
\hline Black & 0.11 & 0.47 & 0.06 & 0.81 & 1.12 \\
\hline Hispanic & 0.18 & 0.44 & 0.17 & 0.68 & 1.20 \\
\hline Other & 0.57 & 0.54 & 1.10 & 0.29 & 1.76 \\
\hline SGM No & REF & REF & REF & REF & REF \\
\hline Yes & -0.00 & 0.38 & 0.00 & 0.99 & 1.00 \\
\hline Male & REF & REF & REF & REF & REF \\
\hline Sex & -0.282 & 0.34 & 0.70 & 0.40 & 0.75 \\
\hline Female & -0.28 & & & & \\
\hline Transgender* & & & & \\
\hline
\end{tabular}

REF $=$ reference group. ${ }^{*}=$ cell size too small for analysis. GPA=grade point average, eCRF $=$ estimated cardiorespiratory fitness

\section{Discussion}

This study aimed to determine if there was a change in participants' physical activity minutes prior to versus after stay-at-home orders were issued in the State of Nevada, to determine if there was a change in depression as measured by PHQ-9 scores prior to versus after stay-at-home orders, and to understand if traditional predictors of depression scores among college students predicted changes in physical activity and depression scores. The most interesting findings from this study were that there was a significant decrease in self-reported minutes of physical activity and worse depression scores in survey participants after the stay-at-home order was issued compared to before the order. Additionally, many characteristics that have previously been shown to impact depression among college students were not significant predictors of worsening depression scores among participants in this study.

Hispanic students were less likely than white students to have a worse PHQ-9 score after the stay-athome order was issued. Previous studies have found that Hispanic students experience cultural stressors that may negatively affect their mental health $[37,38,50]$. For example, after controlling for "general college stress," Hispanic students had "minority-related stress," or negative experiences "linked to social, physical, or cultural attributes salient to the specific minority group individuals identify or are identified 
with" that was uniquely associated with depression [37]. Additionally, Hispanic students are more likely to display the cultural value of familism [51] and are more likely to live at home during college [52]. Previous research has found that familism was protective against depressive symptoms in Hispanic college students and stressed the importance of facilitating such cultural values [50,53]. It is possible that the stay-at-home order enabled some students to spend more time with their families, possibly buffering some of the negative mental health outcomes, though further investigation is needed.

College seniors were also less likely to have increased PHQ9 scores compared to freshmen. The COVID19 pandemic is unprecedented and likely to exacerbate or cause new mental health and stress-related disorders [54], and there is consequently a need to adapt and/or cope with resultant major changes. One potential explanation for the variances in PHQ9 scores by class standing is that the ability to regulate emotions and deploy coping mechanisms increase with age [55]. Additionally, previous studies have found that older adults (except for the oldest old) have lower rates of mental illness compared to young adults $[56,57]$. Thus, seniors may be better "equipped" to handle the stresses of the abrupt adjustments that are required in times of pandemics. Alternatively, it may be that that those students who endure to the standing of college senior are more equipped to handle obstacles and stressors. Research indicates that students who are successful in college have higher emotional and social intelligence $[58,59,60]$. And while it is estimated that only about $60 \%$ of students earn a bachelor's degree within 6 years at the same institution where they started [61], the majority of those who drop out or transfer do so within the first 2 years [62]. Thus, those who are still enrolled and taking courses as a senior likely have a better ability to cope, higher emotional and social intelligence, and consciously chose to remain at said university.

We found that the mean minutes of physical activity were significantly less after the stay-at-home order was issued. While it is possible that the types of physical activities that students were participating in changed, for example, the shut-down of activity centers such as indoor gyms may have resulted in increases in outdoor physical activities or in-home exercise, this does not seem to have led to more overall minutes of physical activity. This is consistent with Huckins and colleagues who used motion sensors in smart phones to track college student's pre- and post-COVID-19 changes and found students to be more sedentary [14], and with Tison and colleagues who used daily step counts from smart phone accelerometers and found that steps decreased worldwide after the declaration of the global pandemic [63]. This particular finding is concerning, as physical activity has consistently been found to prevent depression [43] and reduce depression symptoms in those with mental illness [44]. Given the high rates of depression in college students overall and the worsening depression scores post stay-at-home orders, examining ways to maintain or increase physical activity are warranted.

It is interesting to note that Asian students were more likely than White students to have a decrease in weekly minutes of physical activity after the stay-at-home order. There are at least two possibilities of why this might have occurred. Although we do not know the specific reasons for the reduction in physical activity among members of this group, unprovoked assault on Asians was observed at this point of the pandemic [64]. The effects of news reports, which had made it clear that the COVID-19 originated in China, combined with xenophobic statements from politicians have heightened existing racist attitudes 
towards Asians [65]. To that end, a national news magazine reported several examples of threatening incidents that Asian-Americans living in New York City [66] experienced. Because neighborhood incivilities have been shown to suppress physical activity among Asian-Americans [67], it is likely that aggression toward members of this ethnic group was a factor in decreasing their physical activity after the stay-athome order. Recommendations to reduce xenophobic responses to epidemics include providing accurate information about the disease and speaking out against negative behaviors, such as using caution with regard to narratives that amplify the stigmatization of groups. It should also be stressed that pandemics are a time for solidarity and unity that are based on understanding rather than ignorance [65].

A second potential factor in the pronounced drop in physical activity among Asian students are the behaviors shown by citizens of China, Japan, and Korea. Although little is known about the behavior of Asian-Americans in a time of crisis, those in the three mentioned countries have been shown to exhibit high levels of compliance with stay-at-home orders, mask-wearing, and handwashing directives [68]. If Asians residing in America were similar in conforming to the stay-at-home orders, it is likely that their opportunities for physical activity would have been attenuated and resulted in a reduction of the behavior. Our findings highlight the need to study the physical activity of Asian Americans, especially in times of crisis, and also to study larger societal structures.

This study adds to the understanding of how COVID-19 has impacted college students to date. Its strengths include the use of validated tools to measure depression and physical activity, analysis of predictors of depression and physical activity, and the ability to focus on distinct and formal pre- and post-periods of analysis, since all groups have been affected by COVID-19 and it is therefore impossible to locate an "unexposed" group. However, the results of this study should be interpreted in the context of its limitations. First, the survey relied on a self-reported data, and therefore survey responses may be impacted by recall or social desirability bias. Second, it is possible that the sample is not fully representative, and it is therefore unclear how generalizable these findings are to other college populations: the 194 survey respondents attended one university, self-selected to participate, and were disproportionately female.

The continued impacts of COVID-19 on college students remains largely unknown. Nevertheless, this study suggests that COVID-19 and its consequences may be contributing to reduced physical activity and greater depression symptoms in college students. This study also highlights that among heterogenous college populations, different student groups experience COVID-19 and its consequences differently. It is imperative to continue to research and monitor physical activity and mental health among college students to understand how best to intervene and support this population as we respond to, and eventually recover from, the COVID-19 pandemic. In the meantime, targeted interventions that promote physical activity and support mental health may bolster the ability of college students to cope with these uncertain times and to remain resilient.

\section{Declarations}




\section{Compliance with Ethical Standards}

\section{Disclosures of Potential Conflicts of Interest:}

Funding: No funding was received to complete this study.

Conflicts of Interest: The authors declare that they have no conflict of interest.

Research Involving Human Participants and Informed Consent: This study was approved by the University of Nevada, Las Vegas Institutional Review Board. Prior to starting the survey, participants were provided informed consent materials and had to click "agree" to participate in the survey.

Author Contributions: All authors contributed to the study conception and design, material preparation, data collection, and analysis. All authors also contributed to the first draft of the manuscript, commented on revisions of the manuscript, and read and approved the final manuscript.

\section{References}

1. World Health Organization. (2020, June 1). COVID-19 significantly impacts health services for noncommunicable diseases. https://www.who.int/news-room/detail/01-06-2020-covid-19significantly-impacts-health-services-for-noncommunicable-diseases.

2. The World Bank (2020, June 8). The global economic outlook during the COVID-19 pandemic: a changed world. https://www.worldbank.org/en/news/feature/2020/06/08/the-global-economicoutlook-during-the-covid-19-pandemic-a-changed-world.

3. World Health Organization. (2020, August 15). Coronavirus disease (COVID-19) situation report 208. https://www.who.int/docs/default-source/coronaviruse/situation-reports/20200815-covid-19-sitrep208.pdf?sfvrsn=9dc4e959_2.

4. Mahase, E. (2020). COVID-19: What do we know about "long COVID"?. The BMJ, 370. doi: 10.1136/bmj.m2815.

5. S. Centers for Disease Control \& Prevention. (2020, August 15). Cases in the U.S. https://www.cdc.gov/coronavirus/2019-ncov/cases-updates/cases-in-us.html.

6. S. Government. (2020, July 28). Government response to coronavirus, COVID-19. https://www.usa.gov/coronavirus.

7. Gostin, L. O., \& Wiley, L. F. (2020). Governmental public health powers during the COVID-19 pandemic: Stay-at-home orders, business closures, and travel restrictions. JAMA, 323(21), 2137-2138. doi:10.1001/jama.2020.5460.

8. van Dorn, A., Cooney, R. E., \& Sabin, M. L. (2020). COVID-19 exacerbating inequalities in the US. Lancet, 395(10232), 1243-1244. doi: 10.1016/S0140-6736(20)30893-X.

9. Gupta, S., Hayek, S. S., Wang, W., Chan, L., Mathews, K. S., Melamed, M. L., Brenner, S. K., LeonbergYoo, A., Schenck, E. J., Radbel, J., Reiser, J., Bansal, A., Srivastava, A., Zhou, Y., Sutherland, A., Green, 
A., Shehata, A. M., Goyal, N., Vijayan, A., Velez, J., ... STOP-COVID Investigators (2020). Factors associated with death in critically ill patients with coronavirus disease 2019 in the US. JAMA Internal Medicine, e203596. Advance online publication. doi:10.1001/jamainternmed.2020.3596.

10. Hooper, M. W., Nápoles, A. M., \& Pérez-Stable, E. J. (2020). COVID-19 and racial/ethnic disparities. JAMA, 323(24):2466-2467. doi:10.1001/jama.2020.8598.

11. Volkow, N. D. (2020). Collision of the COVID-19 and addiction epidemics. Annals of Internal Medicine, 173(1), 61-62. https://doi.org/10.7326/M20-1212.

12. The Healthy Minds Network \& the American College Association. (2020). The impact of COVID-19 on college student well-being.

https://www.acha.org/documents/ncha/Healthy_Minds_NCHA_COVID_Survey_Report_FINAL.pdf.

13. Lewis, M., Sanchez, R., Auerbach, S., Nam, D., Lanier, B., Taylor, J., Jaso, C., Nolan, K., Jacobs, E.A., Hudson, F.P., Bhavnani, D (2020). COVID-19 outbreak among college students after a spring break trip to Mexico - Austin, Texas, March 26-April 5, 2020. Morbidity and Mortality Weekly Report, 69(26), 830-835. https://doi.org/10.15585/mmwr.mm6926e1.

14. Huckins, J. F., daSilva, A. W., Wang, W., Hedlund, E., Rogers, C., Nepal, S. K., Wu, J., Obuchi, M., Murphy, E. I., Meyer, M. L., Wagner, D. D., Holtzheimer, P. E., \& Campbell, A. T. (2020). Mental Health and behavior of college students during the early phases of the COVID-19 pandemic: Longitudinal smartphone and ecological momentary assessment study. Journal of Medical Internet Research, 22(6), e20185. https://doi.org/10.2196/20185.

15. Pfefferbaum, B., \& North, C. S. (2020). Mental health and the COVID-19 pandemic. The New England Journal of Medicine, 383(6), 510-512. https://doi.org/10.1056/NEJMp2008017.

16. Buchanan, J. L. (2012). Prevention of depression in the college student population: A review of the literature.Archives of Psychiatric Nursing, 26(1), 21-42.

17. Stallman, H. M. (2010). Psychological distress in university students: A comparison with general population data.Australian Psychologist, 45(4), 249-257.

18. Mazurek Melnyk, B., Slevin, C., Militello, L., Hoying, J., Teall, A., \& McGovern, C. (2016). Physical health, lifestyle beliefs and behaviors, and mental health of entering graduate health professional students: Evidence to support screening and early intervention. Journal of the American Association of Nurse Practitioners, 28(4), 204-211. https://doi.org/10.1002/2327-6924.12350.

19. Ibrahim, A. K., Kelly, S. J., Adams, C. E., \& Glazebrook, C. (2013). A systematic review of studies of depression prevalence in university students. Journal of Psychiatric Research, 47(3), 391-400. https://doi.org/10.1016/j.jpsychires.2012.11.015.

20. Roberts, S. J., Glod, C. A., Kim, R., \& Hounchell, J. (2010). Relationships between aggression, depression, and alcohol, tobacco: implications for healthcare providers in student health.Journal of the American Academy of Nurse Practitioners, 22(7), 369-375. https://doi.org/10.1111/j.17457599.2010.00521.x.

21. Thompson-Ebanks, V. (2017). Leaving college prematurely: The experiences of nontraditional-age college students with depression. Journal of College Student Retention: Research, Theory \& 
Practice, 18(4), 474-495.

22. National Institute of Mental Health (2012). Depression and college students. https://infocenter.nimh.nih.gov/pubstatic/NIH\%2012-4266/NIH\%2012-4266.pdf.

23. National Institute of Mental Health (2019 February). Major depression. https://www.nimh.nih.gov/health/statistics/major-depression.shtml.

24. Gratch, L. V., Bassett, M. E., \& Attra, S. L. (1995). The relationship of gender and ethnicity to selfsilencing and depression among college students. Psychology of Women Quarterly, 19(4), 509-515.

25. Aycock, K.J. (2011). Coping resources, coping styles, mastery, social support, and depression in male and female college students [Doctoral dissertation, Georgia State University]. ProQuest Dissertations Publishing. http://search.proquest.com/docview/899269041/.

26. Peltzer, K., \& Pengpid, S. (2016). Minority stress among lesbian, gay, bisexual, and transgender (LGBT) university students in ASEAN countries: Associations with poor mental health and addictive behavior.Gender and Behaviour, 14(3), 7806-7815.

27. Oswalt, S. B., \& Lederer, A. M. (2017). Beyond depression and suicide: The mental health of transgender college students. Social Sciences, 6(1), 20.

28. Salami, T. K., \& Walker, R. L. (2014). Socioeconomic status and symptoms of depression and anxiety in African American college students: The mediating role of hopelessness. Journal of Black Psychology, 40(3), 275-290.

29. Young, C. B., Fang, D. Z., \& Zisook, S. (2010). Depression in Asian-American and Caucasian undergraduate students. Journal of Affective Disorders, 125(1-3), 379-382.

30. Eldahan, A. I., Pachankis, J. E., Rendina, H. J., Ventuneac, A., Grov, C., \& Parsons, J. T. (2016). Daily minority stress and affect among gay and bisexual men: A 30-day diary study. Journal of Affective Disorders, 190, 828-835.

31. Witcomb, G. L., Bouman, W. P., Claes, L., Brewin, N., Crawford, J. R., \& Arcelus, J. (2018). Levels of depression in transgender people and its predictors: Results of a large matched control study with transgender people accessing clinical services. Journal of Affective Disorders, 235, 308-315.

32. Fingerhut, A. W., Peplau, L. A., \& Gable, S. L. (2010). Identity, minority stress and psychological wellbeing among gay men and lesbians. Psychology \& Sexuality, 1(2), 101-114.

33. Scott, R. L., Lasiuk, G., \& Norris, C. (2016). The relationship between sexual orientation and depression in a national population sample. Journal of Clinical Nursing, 25(23-24), 3522-3532.

34. Ross, L. E., Salway, T., Tarasoff, L. A., MacKay, J. M., Hawkins, B. W., \& Fehr, C. P. (2018). Prevalence of depression and anxiety among bisexual people compared to gay, lesbian, and heterosexual individuals: A systematic review and meta-analysis. The Journal of Sex Research, 55(4-5), 435-456.

35. Plöderl, M., \& Tremblay, P. (2015). Mental health of sexual minorities. A systematic review.International Review of Psychiatry, 27(5), 367-385.

36. Pompili, M., Lester, D., Forte, A., Seretti, M. E., Erbuto, D., Lamis, D. A., Amore, M., \& Girardi, P. (2014). Bisexuality and suicide: A systematic review of the current literature. The Journal of Sexual 
Medicine, 11(8), 1903-1913. https://doi.org/10.1111/jsm.12581.

37. Arbona, C., \& Jimenez, C. (2014). Minority stress, ethnic identity, and depression among Latino/a college students. Journal of Counseling Psychology, 61(1), 162-168. https://doi.org/10.1037/a0034914.

38. Jardin, C., Mayorga, N. A., Bakhshaie, J., Garey, L., Viana, A. G., Sharp, C., Cardoso, J. B., \& Zvolensky, M. J. (2018). Clarifying the relation of acculturative stress and anxiety/depressive symptoms: The role of anxiety sensitivity among Hispanic college students. Cultural Diversity and Ethnic Minority Psychology, 24(2), 221-230. https://doi.org/10.1037/cdp0000175.

39. S. Centers for Disease Control \& Prevention. (2020, August 11). Benefits of physical activity. https://www.cdc.gov/physicalactivity/basics/pa-health/index.htm.

40. Irwin J. D. (2004). Prevalence of university students' sufficient physical activity: a systematic review. Perceptual and Motor Skills, 98(3 Pt 1), 927-943. https://doi.org/10.2466/pms.98.3.927-943.

41. American College Health Association (2020). National College Health Assessment Fall 2019 reference group executive summary. https://www.acha.org/documents/ncha/NCHAIII_Fall_2019_Reference_Group_Executive_Summary.pdf.

42. American College Health Association (2020). National College Health Assessment Fall 2019 reference group data report. https://www.acha.org/documents/ncha/NCHAIII_FALL_2019_REFERENCE_GROUP_DATA_REPORT.pdf.

43. Mammen, G., \& Faulkner, G. (2013). Physical activity and the prevention of depression: a systematic review of prospective studies.American Journal of Preventive Medicine, 45(5), 649-657. https://doi.org/10.1016/j.amepre.2013.08.001.

44. Rosenbaum, S., Tiedemann, A., \& Ward, P. B. (2014). Meta-analysis physical activity interventions for people with mental illness: a systematic review and meta-analysis.Journal Clinical Psychiatry, 75(0), 1-11.

45. Nes, B. M., Janszky, I., Vatten, L. J., Nilsen, T. I., Aspenes, S. T., \& Wisløff, U. (2011). Estimating V·O 2peak from a nonexercise prediction model: the HUNT Study, Norway.Medicine and Science in Sports and Exercise, 43(11), 2024-2030. https://doi.org/10.1249/MSS.0b013e31821d3f6f.

46. Jalene, S., Pharr, J., Shan, G., \& Poston, B. (2019). Estimated cardiorespiratory fitness is associated with reported depression in college students.Frontiers in Physiology, 10, https://doi.org/10.3389/fphys.2019.01191.

47. Spitzer, R. L., Kroenke, K., \& Williams, J. B. (1999). Validation and utility of a self-report version of PRIME-MD: the PHQ primary care study. Primary Care Evaluation of Mental Disorders. Patient Health Questionnaire.JAMA, 282(18), 1737-1744. https://doi.org/10.1001/jama.282.18.1737.

48. Kroenke, K., Spitzer, R. L., \& Williams, J. B. (2001). The PHQ-9: Validity of a brief depression severity measure. Journal of General Internal Medicine, 16(9), 606-613. https://doi.org/10.1046/j.15251497.2001.016009606.x.

49. lorga, M., Dondas, C., \& Zugun-Eloae, C. (2018). Depressed as freshmen, stressed as seniors: The relationship between depression, perceived stress and academic results among medical 
students. Behavioral Sciences, 8(8), 70. doi:10.3390/bs8080070.

50. Corona, R., Rodríguez, V. M., McDonald, S. E., Velazquez, E., Rodríguez, A., \& Fuentes, V. E. (2017). Associations between cultural stressors, cultural values, and Latina/o college students' mental health. Journal of Youth and Adolescence, 46(1), 63-77.

51. Katiria Perez, G., \& Cruess, D. (2014). The impact of familism on physical and mental health among Hispanics in the United States. Health Psychology Review, 8(1), 95-127. https://doi.org/10.1080/17437199.2011.569936.

52. Ovink, S. M., \& Kalogrides, D. (2015). No place like home? Familism and Latino/a-white differences in college pathways.Social Science Research, 52, 219-235.

https://doi.org/10.1016/j.ssresearch.2014.12.018.

53. Castillo, L. G., Conoley, C. W., \& Brossart, D. F. (2004). Acculturation, White marginalization, and family support as predictors of perceived distress in Mexican American female college students. Journal of Counseling Psychology, 51(2), 151.

54. Horesh, D., \& Brown, A. D. (2020). Traumatic stress in the age of COVID-19: A call to close critical gaps and adapt to new realities. Psychological Trauma: Theory, Research, Practice and Policy, 12(4), 331-335. https://doi.org/10.1037/tra0000592.

55. Aldwin, C. (2011). Stress and coping across the lifespan. The Oxford Handbook of Stress, Health, and Coping, 15-34.

56. Kessler, R. C., Mickelson, K. D., Walters, E. E., Zhao, S., \& Hamilton, L. (2004). Age and depression in the MIDUS survey.In O.G. Brim, C.D. Ryff \& R.C. Kessler (Eds.). How healthy are we: A national study of well-being at midlife (pp. 227-251). University of Chicago Press.

57. Westerhof, G. J., \& Keyes, C. L. (2010). Mental illness and mental health: The two continua model across the lifespan. Journal of Adult Development, 17(2), 110-119. https://doi.org/10.1007/s10804009-9082-y.

58. Holt, S. (2007). Emotional intelligence and academic achievement in higher education[Doctoral dissertation, Pepperdine University]. ProQuest Dissertation Publishing. http://search.proquest.com/docview/304707083/.

59. Sparkman, L., Maulding, W., \& Roberts, J. (2012). Non-cognitive predictors of student success in college. College Student Journal, 46(3), 642-652.

60. van der Zanden, P. J. A.C., Denessen, E., Cillessen, A. H.N., \& Meijer, P. C. (2018). Domains and predictors of first-year student success: A systematic review. Educational Research Review, 23, 5777. https://doi.org/10.1016/j.edurev.2018.01.001.

61. S. Department of Education, National Center for Education Statistics. (2020 April). The condition of education, https://nces.ed.gov/programs/coe/indicator_ctr.asp.

62. Bustamante, J. (2019, November 6). College dropout rates. https://educationdata.org/collegedropout-rates/.

63. Tison, G. H., Avram, R., Kuhar, P., Abreau, S., Marcus, G. M., Pletcher, M. J., \& Olgin, J. E. (2020). Worldwide effect of COVID-19 on physical activity: A descriptive study. Annals of Internal Medicine, 
M20-2665. Advance online publication. https://doi.org/10.7326/M20-2665.

64. Campbell, L. (2020, February 9). Chinese in UK report "shocking" levels of racism after corona virus outbreak. The Guardian. http://www.theguardian.com/uk-news/2020/feb/09/Chinese-in-UK-reportshocking-levels-of-racism-after-coronavirus-outbreak.

65. Clissold, E., Nylander, D., Watson, C., \& Ventriglio, A. (2020). Pandemics and prejudice. The International Journal of Social Psychiatry, 66(5), 421-423.

https://doi.org/10.1177/0020764020937873.

66. Kambhampaty, A.P. (2020, June 25). Asian Americans share experiences of racism during COVID-19. Time Magazine. https://time.com/5858649/racism-coronavirus/

67. Kao, D., Carvalho Gulati, A., \& Lee, R. E. (2016). Physical Activity Among Asian American Adults in Houston, Texas: Data from the Health of Houston Survey 2010. Journal of Immigrant and Minority Health, 18(6), 1470-1481. https://doi.org/10.1007/s10903-015-0274-1.

68. Rajib Shaw, Yong-Kyun Kim, \& Jinling Hua. (2020). Governance, technology and citizen behavior in pandemic: Lessons from COVID-19 in East Asia. Progress in Disaster Science, 6. https://doaj.org/article/23a004ad113f418389e18099d180c63d. 